\title{
Politeness of Vietnamese Students in Writing Request Email in English: a Course-based and Socio-pragmatic Study
}

\author{
Thi Minh Trang Pham \\ Vietnam Maritime University \\ minhtrang21095@gmail.com
}

\author{
Aiden Yeh, Ph.D. \\ Wenzao Ursuline University of Languages \\ aidenyeh@gmail.com
}

DOI: http://doi.org/10.36892/ijlls.v2i2.202

\begin{tabular}{|c|c|}
\hline & Abstract \\
\hline $15 / 03 /$ & This exploratory study investigates politeness strategies employed by \\
\hline $\begin{array}{l}\text { Accepted: } \\
\text { 07/04/2020 }\end{array}$ & $\begin{array}{l}\text { Vietnamese EFL learners when writing English request emails sent to foreign } \\
\text { and Vietnamese professors and school staff. A corpus-based critical discourse } \\
\text { analysis is used to analyze sub-elements of politeness including the degree of } \\
\text { imposition, terms of address, request-giving strategy and lexicon-syntactic }\end{array}$ \\
\hline $\begin{array}{l}\text { Keywords: } \\
\text { Politeness; Vietnamese } \\
\text { politeness; Request } \\
\text { email; English as a } \\
\text { Foreign Language; } \\
\text { Corpus-based } \\
\text { discourse analysis }\end{array}$ & $\begin{array}{l}\text { modifier. The results support the assumption that Vietnamese language } \\
\text { pragmatic knowledge is deeply ingrained and has tremendous influence on } \\
\text { students' L2 email writing skills. The study also reveals that Vietnamese } \\
\text { students applied a high level of imposition with formal term of address and } \\
\text { salutation, directness strategies with the overuse of "please" and other } \\
\text { hedges. While gender is not a determining factor, the inflexible adoption of } \\
\text { fixed phrases and syntactic-lexical devices were attributed to the lack of socio- } \\
\text { pragmatic competence. Thus, apart from linguistic knowledge, the role of } \\
\text { cultural awareness and socio-pragmatic knowledge should be highlighted in } \\
\text { communicative English learning and teaching. }\end{array}$ \\
\hline
\end{tabular}

\section{INTRODUCTION}

The latest developments in digital tools and Internet technology have advanced interpersonal interaction in terms of speed, capacity, and the manner in which people communicate and exchange information. One of these multifaceted communication mediums ever invented is email. As email is a combination of both conversational and written language, there are different email writing styles for communicative purposes (Chen, 2001). Likewise, in the field of education, email is gradually being accepted in professor-student interaction, especially in Western colleges due to its adequate formality and convenience (Biesenbach- Lucas, 2006). A large body of research has been conducted on academic emails, notably on the underlying norms and cultural influences in written discourse. Request email, in particular, has garnered extensive studies since it could pose a threat to the receiver's negative face (Brown \& Levinson, 1987), which requires linguistic usage and cultural competence to produce proper request acts which followed social norms.

A request is categorized into a directive act performed to get the hearer to do something for the speaker's benefit (Searle, 1975). As this behavior is "characteristically made in an indirect manner in languages" to fit in the cultural norms (Searle, 1975, as cited in Rajagopalan, 2016, p.281), it has been considered as the most-researched illocutionary act in the existing literature across nations, e.g. England (Blum-Kulka, 1987); America (Chen, 2001); Mexico (Félix-Bradefer, 2005); Taiwan (Tseng, 2016) and Vietnam (Nguyen, 2019; Nguyen \& Ho, 2013). It is an act requiring a speaker to utilize linguistic tools to reduce the 


\section{pragmatic Study}

imposition level and not to impede upon the addressee's negative face (Brown \& Levinson, 1987). Politeness and indirectness, hence, appear to dismiss the threat of losing the hearer's face and please them. However, the degree of politeness and indirectness which the speaker employs predominantly depend on many factors including speaker-hearer relationship, role/status of speaker/hearer and their cultural/ social identities (Chen, 2001).

In the field of English as a foreign language (EFL), the issue of cross-linguistic and cross-cultural disagreement between two interlocutors has recently been studied, especially in the interaction between professors (Westerner - native speakers) and students (Asian - nonnative speakers) via email (e.g. Biesenbach-Lucas, 2007; Tseng, 2016). However, the scale of existing literature is limited in subjects mostly from China and America. For instance, Biesenbach-Lucas (2007) merely interprets the politeness and appropriateness from Western professors' perspectives; she failed to explain how and why Asian students apply politeness strategies to understand the underlying factors looking from Asian maxims of politeness. Additionally, the dearth of literature on email investigation in Vietnamese context formed the basic rationale for the present research. By collecting 42 English emails of 12 Vietnamese EFL learners, this study thrives to examine the politeness strategies employed in academic emails and underlying reasons for their usage. The findings and interpretation of the results may shed some light on the sociolinguistic and cross-cultural issues leading to communication failures.

\section{LITERATURE REVIEW}

\subsection{Face and politeness}

The term "face" was popularized as "the public self-image that every member wants to claim for himself" (Brown \& Levinson, 1987, p.61). In interaction, people need to collaborate to maintain each other's face and defend their faces when being threatened. According to these scholars' politeness theory, there are two aspects of face, namely positive and negative faces. The positive face refers to the need of being appreciated, respected and understood, whereas the negative face concerns the desire to be free from imposition. Request behavior is believed to threaten the hearer's negative face as the speaker asks the addressee to perform an act according to what the speaker desires instead of what the addressee wants (Blum-Kulka \& Olshtain, 1984). Hence, in order to make the request sound less imposing to the hearer's face and get the hearer to comply with the task, the speaker employs politeness strategies.

Considering which aspect of face is being threatened, Brown and Levinson (1987, p.70) characterized two forms of politeness: positive and negative politeness. Positive politeness is an "approach-based" which is directed to the hearer's positive face to enhance the hearer's self-image and fulfil his/her wants. On the other hand, negative politeness consists of avoidance-based strategies, aiming to minimize the imposition level and avoid interfering with the hearer's freedom of action. Besides these two forms of politeness, the speaker can use a bald on-record politeness strategy on which s/he express baldly, unambiguously and directly without any mitigating devices. Bald-on-record method is reported to mainly employed in intimate relationship such as close friends and family since it is the most facethreatening action (Cutting, 2002). In contrast to bald-on-record strategy, off-record implies an indirect way of speaking when the speaker indirectly makes an offer or demand to the hearers. In this case, the hearer is required to understand the implication in the speaker's talk.

It is noteworthy that even though the notion of negative politeness ties to indirectness, indirect statement is the highest degree of politeness or the most effective way in communication (Yu, 2011). Blum-Kulka (1987) defined politeness as a balanced hybrid of pragmatic clarity and avoidance of using force or threat language. Many studies reveal that some cultures and languages including Russian (Ogiermann, 2009) and Korean (Kim, 2011) prefer pragmatic clarity which is direct imperative with proper intonation, addressing and honorifics to avoid communication failure. At the same time, Americans and Australians are likely to advocate the use of conventional indirectness in requests (Watts, 2003), however, 
camaraderie is still addressed. Therefore, there is no standard politeness or fixed indirectness level for all cultures and languages. Accordingly, researchers should abstain from stereotypical views and generalizations about Asian and Western cultures.

\subsection{Politeness and indirectness in Vietnam}

In concord with the claim that interaction in East Asian context (China in particular) is somehow implicit, indirect and receiver-centered (Miike, 2006), communication in Vietnam is also influenced by Confucian ideology and Chinese precept of politeness.

Traditionally, Confucian philosophy began its vigorous influence on Vietnamese tradition owing to the invasion of China in the first century and the support of feudal governments in the 11th century (Hieu, 2015). Hence, the notion of lễ (禮) (etiquette) has become the most important factor to cultivate a well-mannered and civilized person. Owing to Confucian philosophy, Vietnamese politeness involves appropriate formal speech (addressing, honorifics, and expressions) and non-verbal behavior (gesture, attitude and posture) (Ky, 1883, as cited in Chew, 2011). For Vietnamese people, especially those from the North, proper politeness act consists of four elements namely "lễ phép" (respectfulness); "đúng mức" (propriety); "tế nhị" (delicacy) and "khéo léo" (tactfulness) (Vu, 1997, p.28). Those values are carefully taught and widely practiced in family, institution and society. In family, young children are expected to behave in appropriate attitude toward older people by addressing suitable kinship terms and honorifics in family. Rules including "kính trên nhường dưới" (respect the older/superior and yield the younger/subordinate) and "biết trên biết dưới" (know your and the other's social status/ standing) need to be mastered. Otherwise, they are assumed to be "hỗn" "vô lễ" (disrespectful) or "vô giáo dục" (uneducated). Furthermore, schools also contribute to spread the notion of politeness by asking students to respect teachers, school staffs and the elders. This is reiterated in the must-cited dictum in every primary to high school that says "Tiên học lễ, hậu học văn" (first, a person must learn to master rules/ etiquette, then s/he can acquire academic knowledge). This means appropriate social behavior is put in a more important position than good academic performance. In social scale, the aim for many Northern cities is to build a "thành phố văn minh lịch sự" (civilized and polite city), and if dwellers hold inappropriate manners, they may be associated with the term "nhà quê" (uncivilized) (Chew, 2011, p.213). All in all, Vietnamese politeness advocates respectfulness and follows a "group-oriented rather self-oriented" approach to construct social harmony (Nguyen \& Ho, 2013, p.689).

In terms of negative politeness, Vietnamese people avoid conflicts and acts of intimidation that can threaten people's 'face' by emphasizing "tình cảm" (sentiments) in communication. The notion of sentiment improves the relationship between neighbors, colleagues, relatives, social contacts and even acquaintances (Chew, 2011). Sentiment consists of the use of proper greeting, addressing and decency to show sincerity, caring and mutual help toward the addressers. In linguistic use, "tế nhị" (delicacy) and "khéo léo" (tactfulness) by showing sincerity and care are crucial to respect and maintain solidarity with the hearer, at the same time, to help the speaker achieve communication purpose. This is when indirectness is summoned, especially in request behavior.

\subsubsection{Address and honorifics in Vietnamese language}

Previous literature (Chew, 2011) has mentioned an indispensable role of proper use of address term(s) in Vietnamese language, following the rule "xưng nghiêm hô tôn" (when addressing yourself, be humble; when addressing others, be respectful). Thus, before delving into any analysis and interpretation of Vietnamese politeness, it is necessary to have a general understanding of the terms of address and honorifics.

The Vietnamese linguist Luong (1987) argued that the Vietnamese system of address and reference is noticeably obscure. Different from English language with "I" and "you" for 


\section{pragmatic Study}

personal pronoun, Vietnamese language system has many linguistic terms including personal pronouns, kinship and status terms, and proper nouns for personal names (Luong, 1987). Nevertheless, due to the scope of the study, only examples related to teacher-student interaction were discussed to avoid confusion. When interacting with a teacher, the more inferior regarding age and social status toward the hearer, the humbler the speaker should be. For all of the students no matter what ages and social status they have, they are obligated to address cô/ thầy (teacher) + first name or giáo sư/ tiến sĩ (professor/ doctor) + first name in higher education institution, which is somehow less formal than Chinese language (tittle + family name) (Nguyen, 2011).

Honorific in Vietnamese language follow a hearer-centered approach which implies that the speaker directs the honorific to the hearer (Le, 2011). There are many politeness markers including "dạ" (polite marker for yes), "dạ thưa" (Sir/ Madam, respectful humble) and "xin" (supplicate/ please for begging) (Do, 1994, p. 168). Regarding request behavior, the marker "xin" is usually utilized to lessen the imperative act. By using "xin", the addresser shows a humble attitude toward the addressee to beg for permission or help ( $\mathrm{Vu}, 1997)$. Besides, when interacting with an addressee with older/ higher ranking or social status, the speaker is required to add "ạ" (honorific marker) at the end of sentences. In short, despite holding different degrees of politeness, formality and strength, these honorific particles all serve the function of making the speaker appear to be polite and humble. This may lead to the hearer's sense of being respected and superior (Le, 2011). In general, by looking at the use of terms of address and honorifics, Vietnamese language system illustrates a strong adherence to respectfulness and formality.

\subsection{Previous studies about academic request email}

Since a request act could threaten the addressee's negative face, politeness strategies employed by the addresser are postulated. However, owing to the differences in social norms and language, as non-native English speakers, Vietnamese students may encounter problems when writing emails to native English professors.

There is an exponential growth of interest in comparing the native students (NS) and non-native students (NNS) in their request emails to native English professors. One of the widely used frameworks used in such studies was that of Blum-Kulka, House and Kasper's (1989) Cross-Cultural Speech Act Realization Project (CCSARP). Applying CCSARP framework, Biesenbach-Lucas (2007) conducted a large-scale corpus study of 533 emails (382 NS; 151 NNS - mostly Asian) to compare NS and NNS's politeness strategy use in emails. NNS tend to overuse set phrases including "could you", "would you" in every request context. Besides, a large number of NNS adopt improper lexical choices by misusing the word "please". The researcher even clarifies that these problems may derive from lack of academic email teaching and linguistic knowledge. However, the study's findings only originate from students' emails sent to one particular professor, which may neglect the variance of how students correspond to different teacher, gender, age and email settings (cf. Baugh, 2011).

Another most-cited research of Chen (2001) between NS (American) and NNS (Taiwanese) applying the traditional approach (using Brown \& Levinson's model) reveals intriguing findings and implications. As the Chinese maxim of respectfulness deeply ingrains in Taiwanese students' brain, they address professors by title + last name, as opposed to American students calling their teachers by their first name. Chen $(2001, \mathrm{p} .13)$ concludes that their Chinese pragmatic knowledge is carried over "in an automatic and unconscious way" whenever they use the English language in writing academic emails. Sharing the same notion of first language (L1)-second language (L2) pragmatic knowledge, Baugh (2011) highlights the lack of socio-pragmatic knowledge. This knowledge, according to Leech (1983), is the understanding about social norms and practice in a particular communication context of 
overseas students as they acquire language for testing purpose before their departure to America.

Apart from language and pragmatic competence, gender also reinforces politeness patterns. The existing literature reports conflicting findings on gender-driven factors in request-making act. As claimed by Hamiloğlu and Emirmustafafaoğlu (2017), females produce higher formality in address, considerate thanking/ closing remarks and more indirectness. Other researchers (e.g. Holmes, 1995; Shams \& Afghari, 2011) support this claim by stating that in verbal communication, women evidently show more concern about the addressee's face and maintain relationship. Consequently, they are likely more indirect and use positive politeness to reduce face-threatening acts (Mohammadi \& Tamimi, 2014). Contradictorily, other studies exhibit no significant differences between genders in request writing manner (Rahmani \& Rahmany, 2014). It is noteworthy that gender comparison is only conducted in Iraq, Iran, Turkish and English-speaking countries, leaving a gap in Asian context in which English is a foreign/ second language.

\subsubsection{Framework for analyzing request email}

Akin to Brown and Levinson's (1978, 1987) statement confirming the close relationship between politeness and directness, Blum-Kulka, House and Kasper's (1989) CCSARP framework classifies request strategies based on the directness level of the imposition act. However, to fit with the scope of the present study, the modification of CCSARP proposed by Biesenbach-Lucas (2007) is applied. Biesenbach-Lucas's (2007) coding category for directness level and modifiers is more suitable for request act in written communication.

There are three directness levels including direct, conventionally indirect and nonconventionally indirect (hints) with different strategies as presented in Table 1.

\section{Table 1. Coding category for directness level}

\begin{tabular}{|c|c|c|}
\hline $\begin{array}{c}\text { CCSARP } \\
\text { Directness Level }\end{array}$ & Request Strategies & Examples \\
\hline \multirow[t]{7}{*}{ Direct } & Imperatives & Please extend the due date. \\
\hline & Elliptic constructions & Any comments? \\
\hline & Performatives & I feel I have to ask for an extension for a week \\
\hline & Direct questions & When do you have time? \\
\hline & Want statements & $\begin{array}{l}\text { I want to set up a meeting with you. } \\
\text { I would like to suggestions }\end{array}$ \\
\hline & Need statement & I will need an extension. \\
\hline & Expectation statement & $\begin{array}{l}\text { I hope you'll give me the weekend to finish } \\
\text { typing my work. }\end{array}$ \\
\hline $\begin{array}{l}\text { Conventionally } \\
\text { indirect }\end{array}$ & $\begin{array}{l}\text { Query preparatory } \\
\text { (ability, willingness, } \\
\text { permission) }\end{array}$ & $\begin{array}{l}\text { Could I meet with you next Tuesday? } \\
\text { Would you mind to take a look and give me } \\
\text { some suggestions? }\end{array}$ \\
\hline Hints & $\begin{array}{l}\text { Strong hints/ mild } \\
\text { hints }\end{array}$ & $\begin{array}{l}\text { Attached is a draft of my grammar lesson } \\
\text { plan. } \\
\text { I'm having a very difficult time in figuring out } \\
\text { how to put these lesson materials together. }\end{array}$ \\
\hline
\end{tabular}

(Biesenbach-Lucas, 2007, p.67)

In the most explicit level, the speaker expressly requests what the hearer is expected to perform. These direct request strategies can be recognized by syntactic markers including imperatives and verbal means such as direct questions and want/ need statements. 


\section{pragmatic Study}

Conventionally indirect request is realized by "reference to contextual preconditions necessary for its performance, as conventionalized in a given language" (Blum-Kulka \& Olshtain, 1984, p.201). The speaker making this kind of request act mostly starts his/her utterance with auxiliary verbs "could" and "would". The last level - hint - refers to the request which could be interpreted only basing on contextual clues. For instance, to order the hearer to close the window, the speaker can utter "Why is the window open?". When mentioning about the window, s/he "partial reference(s) to object or element needed for the implementation of the act". The speaker may even "reliance on contextual clues" by saying "It is cold in here" to address the hearer perform the act. (Blum-Kulka \& Olshtain, 1984, p.201).

Additionally, these scholars propose a category for syntactic and lexical devices which are frequently employed in order to lighten the imposition. To be specific, for syntactic devices, the speaker favors the past tense and the progressive form of verbs such as "Could you ..." or "I am looking forward" rather than "Can you" or "I look forward". Furthermore, embedding refers to the act in which a clause (or clauses) is included in another. This process can be observed in giving a request constructed by a multi-clause statements such as "I wonder whether you could meet me today" and "Ring me when you are at the office". The lexical modifiers are sorted into six types according to their function in speech act. Beside the most used word "please", downtoners, understaters and hedges (some, any, somehow) are included in the request statement to exert the mitigation effect on the request statement. Last but not least, the speaker can show his/her subjectivity through subjectivizers (I was wondering/ I think) or seeking for the hearer's opinion by using consultative devices (do you think/ Is there a chance). Table 2 indicates how syntactic and lexical modifiers are classified.

Table 2. Coding category for syntactic and lexical modifiers

$\begin{array}{ll}\text { Syntactic modifiers } & \begin{array}{l}\text { past tense } \\ \text { progressive aspect } \\ \text { embedding }\end{array} \\ & \begin{array}{l}\text { please } \\ \text { downtoners: possibly, maybe, perhaps }\end{array} \\ & \text { understaters: just, a little, a minute } \\ \text { Lexical modifiers } & \begin{array}{l}\text { subjectivizers: I was wondering, I think/feel, I wanted to know } \\ \text { consultative devices: do you think, is there a chance } \\ \text { hedges: some, any, somehow }\end{array}\end{array}$

(Biesenbach-Lucas, 2007, p.67)

Prior researchers tend to use only CCSARP in politeness investigation. However, considering email as a special discourse whose structure could account for the degree of politeness, the degree of imposition could be indicated through the email structure (see Table $3)$.

Table 3. Coding category for the degree of imposition

$\begin{array}{ll}\text { A request with low degree of imposition } & \text { A request with high degree of imposition } \\ \text { 1. Getting attention } & \text { 1. Getting attention } \\ \text { 2. (Supportive sentences) } & \text { 2. (Small talk) } \\ \text { 3. Requesting } & \text { 3. Supportive sentences } \\ \text { 4. Thanking } & \text { 4. Requesting with modifications } \\ & \text { 5. Thanking } \\ & \text { 6. (Closing a conversation) }\end{array}$

(Elmianvari \& Kheirabadi, 2013, p.378)

These researchers merely depend on the request statement to categorize the whole email falling into low or high degree of imposition group. Instead, other email elements such as getting attention, supporting sentences, requesting statement, thanking and closing signals 
are indeed worth considering. The higher imposition the email request is, the more politeness level it is rated. More importantly, supportive sentences in low degree of imposition emails are sometimes ignored by the writers, though, they are the heart of respect behavior in high degree of imposition emails. Supporting sentences refer to politeness strategies in which the sender uses to persuade the receivers. These sentences imply the following actions:

- ask the potential availability of the hearer or ask for the hearer's permission to make the request. (Are you busy right now? I have got a question to ask you. Could you do me a favor?)

- give a reason or an explanation for your request. (I missed the class yesterday. Could you give me a handout?)

- promise a reward for the hearer if the request is carried out. (Could you give me a lift? I'll pay for the gas or take you out to dinner).

- reduce the imposition placed on the hearer by the speaker's request. (A: Maybe this weekend. B: This weekend works fine. Whatever works for you).

(Elmianvari \& Kheirabadi, 2013, p.379)

Notably, gift-giving strategy is not listed as a kind of supporting sentences above although it is proved to be a popular strategy used by Asian students, especially Vietnamese students in particular (Nguyen, 2019; Nguyen \& Ho, 2013). Gift-giving indicates the action of showing the speakers' admiration, affection, care and sympathy to the hearer, resulting in the fulfilment of what the hearer wants (Brown and Levison, 1987). Thus, it should also be listed as a supporting element in email request.

\subsubsection{Previous studies on request behavior in Vietnamese context}

Nguyen and Ho (2013) investigate the way Vietnamese people exhibit their politeness and indirectness in verbal communication in their own mother tongue. By asking Vietnamese students to act in hypothetical situations, the researchers confirm the predominant usage of syntactical and lexical markers including terms of address, honorifics and modal particles (interrogatives, supportive moves and hedges). These strategies are utilized following the maxim of Vietnamese politeness when the speakers act regarding to the hearer's social status and relationship with the speaker. Particularly in the cases when the hearers are older or in higher social position, lexical markers appear frequently in direct request to mitigate imposition and exhibit their concern for hearers' face.

As for Vietnamese people using English as a foreign language, there is only one study of Nguyen (2019) on students' English request emails revealing many patterns of politeness. In this study, Vietnamese students employ indirect politeness owing to Vietnamese's notion of politeness. To be specific, there is a high occurrence of using phatic communication strategies (e.g. How are you/ How's your teaching), "gift-giving" politeness strategy (e.g. I really like this subject), formal thanking and closing remarks. However, the author admits that the corpus is collected from the students majoring in Translation and Interpretation Studies in the same university, so the same writing strategies learned in writing courses may have been used. Moreover, the study focuses on analyzing the email structure instead of request strategies and discourse markers.

To sum up, there is little investigation on politeness in English request emails written by Vietnamese students. It is crucial that we look at politeness from a more comprehensive approach with request strategies and linguistic markers, and also examine whether there are gender-based differences in email discourse usage by Vietnamese L2 learners.

\subsection{Statement of research problem and hypothesis}

As stated earlier, it is evident that Vietnamese language and culture influence email writing process. However, inadequate corpus-based as well as authentic data has been collected and analyzed, especially in Vietnamese context. Not enough research has been done 


\section{pragmatic Study}

exploiting the politeness strategies employed by Vietnamese students with heterogeneous background in terms of gender and major. Thus, this research aims to (1) fill in the gap of literature in Vietnamese context (2) investigate politeness strategies applied by different genders (2) shed some light into the cross-cultural pragmatic/ socio-pragmatic field. To achieve these ultimate goals, this study attempts to solve the following questions:

- What politeness strategies do Vietnamese learners employ in writing English request emails regarding the degree of imposition, terms of address, request-giving strategy and lexicon-syntactic modifier?

- Are there any gender-based differences in writing English request emails written by Vietnamese EFL learners?

- Are there any differences in writing English request emails of English-major and nonEnglish-major Vietnamese EFL learners?

\section{METHODS}

\subsection{Participants}

Based on the purposes of this study, participants were chosen following specific criteria. They (1) are all Vietnamese undergraduates and graduates, (2) have experience of studying abroad (for the sake of diverse background of the addressee) and (3) are willing to share their emails. Since emails may contain personal information, the present study employed purposive sampling method. Specifically, the researcher made use of her social network to recruit suitable participants for the study. Chosen participants were asked to sign a consent to ensure the use of their emails merely for research purpose. To protect participants' identity, all the personal information in data is either omitted or pseudonymized. Details of participants are listed in table 4.

\section{Table 4. Description of participants}

\begin{tabular}{|c|c|c|c|c|c|}
\hline No & Gender & Age & Major & $\begin{array}{c}\text { Addressees' } \\
\text { nationality }\end{array}$ & $\begin{array}{l}\text { Number } \\
\text { of emails }\end{array}$ \\
\hline 1 & Female & 24 & $\begin{array}{l}\text { English Language Teacher } \\
\text { Education }\end{array}$ & $\begin{array}{l}\text { Vietnamese, } \\
\text { Dutch, Belgian }\end{array}$ & 3 \\
\hline 2 & Female & 24 & Interpretation in English & American, British & 7 \\
\hline 3 & Male & 25 & Computer science & Australian, Indian & 4 \\
\hline 4 & Male & 24 & Petroleum Technical Studies & Russian & 3 \\
\hline 5 & Male & 22 & Computer science & American & 3 \\
\hline 6 & Male & 22 & Business & Australian, Korean & 3 \\
\hline 7 & Female & 24 & Supply Chain Management & France, American & 4 \\
\hline 8 & Female & 24 & $\begin{array}{l}\text { Earth and Environmental } \\
\text { Science }\end{array}$ & Vietnamese & 1 \\
\hline 9 & Male & 25 & $\begin{array}{l}\text { Earth and Environmental } \\
\text { Science }\end{array}$ & $\begin{array}{l}\text { Belgian, } \\
\text { Vietnamese }\end{array}$ & 3 \\
\hline 10 & Female & 24 & $\begin{array}{l}\text { Vietnamese Studies/ English } \\
\text { Language } \\
\text { Education }\end{array}$ & $\begin{array}{l}\text { Indonesian, } \\
\text { Vietnamese }\end{array}$ & 3 \\
\hline 11 & Female & 24 & $\begin{array}{l}\text { English Language Teacher } \\
\text { Education }\end{array}$ & $\begin{array}{l}\text { Chinese, } \\
\text { American, } \\
\text { Canadian }\end{array}$ & 3 \\
\hline \multirow[t]{2}{*}{12} & Male & 23 & $\begin{array}{l}\text { English Language Teacher } \\
\text { Education }\end{array}$ & Belgian, French & 5 \\
\hline & & & & Total & 42 \\
\hline
\end{tabular}


The table above illustrates the balance in gender (six females -21 emails, six males 21 emails) and diversity in majors (eight majors from eight universities). Participants are either undergraduates or graduate students who have studied abroad for a semester/ a year with ages ranging from 22 to $25(\mathrm{M}=23.8)$. Furthermore, according to the description of the addressees, there is considerable diversity in their cultural background. Notably, in the collected email corpus, addressees are either professors $(n=31 ; 72 \%)$ or admission officers/ program coordinators $(\mathrm{n}=12 ; 28 \%)$.

As reviewed above, the notion of politeness in Vietnam evidently ties with age and social status. The participants' ages ranging from 22 to 25 , and their recipients are university professors. Hence, the collected email corpus is written by people holding a lower status sending to people holding a higher status regarding age and their social ranking.

\subsection{Data collection and selection}

In early October 2019 to early November 2019, 148 emails for different purposes (request, thanking, announcing, apologizing, etc.) in both Vietnamese and English language were collected, and only 42 English request emails were retrieved. The participants were later asked to provide their personal information for the research purpose.

\subsection{Data analysis}

This study applied corpus-based critical discourse analysis - as a theoretical framework combining both quantitative and qualitative approaches. Using the corpus-based approach in linguistics enables researchers to strengthen the results by providing sufficient empirical support (Stubbs, 1996). By quantifying data, especially when investigating the typicality of lexical and grammatical devices, linguists can make claims with a high degree of objectivity rather than from their subjective feelings (Lee, 2008). On the other hand, perceived language as "a socially conditioned process, conditioned that is by other (nonlinguistic) parts of society" (Fairclough, 1989, p.22), critical discourse analysis approach claims an intertwined relation between discourse and society. Therefore, it is evident to claim that corpus-based critical discourse analysis is a useful tool for the present study which focuses on politeness as a social practice and how it pragmatically displays in L2 discourse.

As politeness is an arduous concept, only some fundamental factors of politeness were analyzed, namely the degree of imposition, term of address, request strategies and lexiconsyntactic modifiers. Coding categories of Elmianvari \& Kheirabadi (2013) and BiesenbachLucas, (2007) is used as follows:

Degree of imposition: This study employed the coding scheme for high and low degrees of imposition in email request suggested by Elmianvari \& Kheirabadi (2013).

Term of address: It is believed the more formal the address is, the more the request it is. Formal terms of address are Dr., Miss., Sir/ Madam, Professor + last name. For informal addresses, this study refers to the way the writer calls the receiver with nicknames, first names or abbreviations such as Prof., Teach, Doc. (Hamiloğlu \& Emirmustafafaoğlu, 2017).

Directness: Request directness level is evaluated according to CCASARP with different strategies as reviewed above.

The study analyzes 42 emails one by one by coding and counting the frequency appearing in each email. After analyzing the request email corpus, a comparison between male and female participants and among English-major and non-English-major students is reported. 


\section{FINDINGS AND DISCUSSION}

The quoted texts from the samples were from the participants' emails which were not corrected in any form to retain the original text. Thus, if there are any grammatical or spelling errors, those were from the participants.

\subsection{Degree of imposition and formality of address}

Based on the coding category of Elmianvari \& Kheirabadi (2013), each email is analyzed accordingly. These examples in Appendix 1 illustrate how an email is coded as high or low level of imposition email.

The researchers manually calculated the frequency of employing each element of all emails. If one kind of supporting sentences appears more than once in an email, the researchers only count as one. The quantified data in Table 5 is later double-checked by other scholars to ensure the accuracy of the counting process. As differences between genders are the focus of this study, the data is reported accordingly.

\section{Table 5. The frequency of email elements regarding genders}

\begin{tabular}{clcc}
\hline \multicolumn{2}{c}{ Number of collected emails } & $\begin{array}{c}\text { Female } \\
(\mathbf{n = 2 1})\end{array}$ & $\begin{array}{c}\text { Male } \\
(\mathbf{n = 2 1})\end{array}$ \\
\hline \multirow{2}{*}{ Getting attention } & Formal & 19 & 17 \\
\cline { 2 - 4 } & Informal & 2 & 4 \\
\hline \multirow{2}{*}{$\begin{array}{c}\text { Supporting } \\
\text { sentence }\end{array}$} & Asking for permission/ avalability & 2 & 0 \\
\cline { 2 - 4 } & Explanation & 19 & 16 \\
\cline { 2 - 4 } & Promise reward & 4 & 5 \\
\hline & Asking for forrgiveness & 4 & 2 \\
\hline & Gift-giving & 2 & 5 \\
\hline & Thanking & 20 & 16 \\
\hline & Closing remarks & 19 & 14 \\
\hline
\end{tabular}

\subsubsection{Getting attention (Salutation \& term of address)}

As we can observe from the table above, all participants include the "getting attention" part in their email which includes salutation and term(s) of address. To judge the formality of "getting attention", the researchers follow the theory of Brown and Levinson (1987) stating informal address terms involving denoting in-group identity (mate, guy, brother etc.) and formal terms including those which aim to "give deference" to the addressee (Sir, Teacher, Professor). Hence, the "getting attention" phrases such as "Hi, Jane" and "Morning, Mark" are considered informal.

Formal address terms and salutation are favored by the majority, especially the phrase "Dear Professor/ Teacher/ Dr. + first name/ last name/ full name" and "Dear Mr./ Ms. + first name", which concords with Nguyen's (2019) findings. Interestingly, some students even advocate the use of "Sir/ Madam" to show their deepest respect to their professors. This phenomenon could be influenced by Vietnamese culture patterns mentioned in Literature Review. Influenced by Confucian philosophy, the Vietnamese are required to exhibit respectfulness to high-status or older people through proper address terms to avoid being called uneducated and uncivilized (Nguyen, 2011). It is a social obligation for students to call their teacher as "Teacher/ Professor/ Doctor + first name" (not last name as in Chinese culture). Thus, this fact explains why some participants address their teachers by their first name. 
Interestingly, a quarter of emails ( $\mathrm{n}=11,26.7 \%$ - non-major males) start with "Dear/ Good morning + Professor/ Mr/ Ms + first name + last name" which is very unusual and even impolite in some Western culture (e.g. German culture) (International Office of Goethe University Frankfurt, n.d.) and even in Vietnam. One possible explanation is the distinctiveness in English and Vietnamese names. Specifically, the English family name is put behind the given name, whereas the Vietnamese family name is put first, followed by the given name as follows:

\begin{tabular}{ccc}
\hline Hoang & Viet & Tung \\
\hline Last name/ Family name & Middle name & Given name/ First name \\
\hline
\end{tabular}

Thus, as a non-native English speaker, Vietnamese students may encounter confusion when it comes to English names. They use the professor's full name to ensure the polite term of address yet leading to unexpected adverse consequence.

\subsubsection{Supportive sentences}

Making explanation is utilized with high occurrence by both females and males with $90.4 \%$ and $71.4 \%$ respectively. In this email corpus, explanation acts as an effective strategy to (1) create contextualized and mutual understandings between speaker and hearer and (2) persuade the hearer to do the requested act later. An email of participant 3 (Male - Computer Science major) reveals the above functions of explanation:

Hi [first name of the addresser], (Getting attention - Informal address)

I'm currently a first-year PhD student from [name of old class] (now [name of new class])

I'm doing research about smart home, the problem that I am solving right now is anomaly detection (fall detection, forgetting activities, etc.) (Supporting sentence - Explanation)

The input dataset comes from ambient sensors (motion sensors, etc.) so what I'm finding is a simulation tool that can simulate home environment and activity scenarios. Using the simulation tool, I can create dataset based on predefined scenarios and verify if my algorithm can detect abnormal events. Another idea for creating abnormal testing data is to inject synthetic abnormal events into real data. (Supporting sentence - Explanation)

I understand that the collected data cannot be shared (Supporting sentence) In that case, I'm happy if you can share any tool that is relevant to my concerns. (Request - Indirect)

Thank you very much. (Thanking)

Kind regards, (Closing remark)

[Student's full name]

The email is coded "high imposition" with high level of politeness owing to clear and appropriate email structure and use of supporting sentences. According to the above example, this student successfully entails sufficient details of his research (topic, method and arising problems), which provides the Australian lecturer with a general context before being imposed. Mutual understanding and sense of trust are established as participant 3 explicitly clarified his research and sincerely exhibit his awareness and concern toward the research ethics (I understand that the collected data cannot be shared). The student, later, suggests his appreciation (I'm happy if you can share any tool that is relevant to my concerns) if the request is accepted. The request is conventionally indirect by querying the receiver's willingness toward the act (share any tool that is relevant to my concerns), followed by thanking and formal closing remarks indicating a high level of politeness despite the informal 


\section{pragmatic Study}

term of address and salutation. With many supportive sentences (explanation; promise a reward) and indirect request statement to show sincerity and care, participant 3 exposes his delicacy and tactfulness to achieve his goal, which is accordant to the notion of lê̂ (禮) in Vietnamese politeness strategy.

This result is in line with the findings of Hamiloğlu and Emirmustafafaoğlu (2017) when examining emails of Turkish EFL undergraduates when giving reasons is favored the most. Similar to politeness strategy - "Give (or ask for) reason" in Brown and Levinson (1987, p. 128), giving explanation aims to engage the hearer in the context by "including $\mathrm{H}$ thus in his practical reasoning, and assuming reflexivity (H wants S's wants)", "assuming cooperation" as "a way of showing what help is needed". On the one hand, the other four strategies listed above are sometimes considered as triggering a sense of being manipulated or treated insincere. Giving reasons, on the other hand, provides hearers a chance to evaluate the situation or argument their view (Jansen \& Janssen, 2010). Thus, comparing to strategies such as flatters and hints for cooperation, providing reasons before doing a FTA helps the speaker persuade the listeners to perform the act in most cases (Petty \& Cacciopo, 1984).

Regarding the other types of supporting sentences, promising a reward and gift-giving sentences are rarely employed. There are five emails from male participants and only two emails of females using gift-giving strategies (positive politeness), which contradicts Nguyen's (2019) study. These findings are also inconsistent with Mohammadi and Tamimi's (2014) affirmation that positive politeness often appears in women's request rather than men's.

\subsubsection{Thanking and Closing Remarks}

As for the closings, all participants show their appreciation for receivers by adopting the same expression of gratitude. "Thank you", "Thank you so much" and "Thank you for your time" take up the largest share of distribution. There are merely two male students who do not show any thanking expressions while all female participants include formal gratitude expressions in their request email. This somehow confirms the statement of Hamiloğlu and Emirmustafafaoğlu (2017) theorizing that females adopt a more formal address and substantial thanking and closing remarks thanks to their sensitiveness and concern about the addressee's face (Holmes, 1995).

However, the emails of male students are still written in a high level of imposition. Lack of thanking might indicate informal and even impolite gestures of the writer, yet other closing elements such as closing remarks and signals are employed. This reveals male students' concern about the reader's face. For example, three emails from participant 5 (Male - Computer Science) in Appendix 2 indicate the deficiency of thanking expression but reveal appropriate politeness in writing tone. As evidenced in these emails, a formal writing tone is adopted by effective use of formal "getting attention" part, supporting sentences and request behavior, although there is no gratitude expression. It is noticeable that the phrase "I (am) look(ing) forward to hearing from you/ your reply" (email 1 and 3) is frequently detected as a fixed phrase at the end of both male and female's email. Their hope for the addressee attaining the request, in this case, is shown. These kinds of complementary closing are also found in Nguyen (2019) to enhance the receiver's positive face; hence, appearing to be a popular politeness strategy used by Vietnamese students regardless of their genders.

There are nine emails that omit closing remarks and end with the student's full name. This discloses the influence of Vietnamese language on English emails. Except for business emails, the Vietnamese neglect to use closing remarks to avoid the sense of extreme politeness and formality. Instead, people normally end their writing with thanks or wishes before signing-off. This supports the theory of Chen (2001) and Baugh (2011) about the unconscious transferability of L1 pragmatic knowledge when writing in L2 context of EFL learners. 
Overall, there are 37 emails (88.1\%) coded as high level of imposition emails with high levels of politeness. The rest is categorized as either moderate or low level of imposition. This result reveals a high politeness level in email writing structure of Vietnamese students regardless of genders. It also reflects Vietnamese culture with a strong emphasis on formality and respectfulness to achieve social harmony (Nguyen \& Ho, 2013).

\subsection{Directness level and syntactic and lexical devices}

In this section, requesting expressions are retrieved and coded following CCSARP framework modified by Biesenbach-Lucas's (2007). The researchers reported both directness level and syntactic-lexical devices to see discourse devices in conjunction with the choice of request strategies. The results of directness level of the corpus are shown in Table 6 . Particularly, some participants utilize more than one request strategy in one email.

\section{Table 6. The frequency of request strategies based on gender}

\begin{tabular}{|c|c|c|c|c|c|}
\hline & & $\begin{array}{c}\text { Female } \\
(n=21)\end{array}$ & $\begin{array}{c}\text { Male } \\
(n=21)\end{array}$ & \multicolumn{2}{|c|}{ Total } \\
\hline \multirow{7}{*}{ Direct } & Imperative & 5 & 9 & $33.3 \%$ & \multirow{7}{*}{$57.1 \%$} \\
\hline & Elliptic construction & $\boldsymbol{0}$ & 0 & $0 \%$ & \\
\hline & Performatives & $\boldsymbol{0}$ & $\boldsymbol{0}$ & $0 \%$ & \\
\hline & Direct question & $\boldsymbol{0}$ & 0 & $0 \%$ & \\
\hline & Want statement & 1 & 3 & $9.5 \%$ & \\
\hline & Need statement & $\boldsymbol{0}$ & 0 & $0 \%$ & \\
\hline & Expectation statement & 1 & 5 & $14.3 \%$ & \\
\hline Conve & nally indirect & 12 & 8 & $47.6 \%$ & $47.6 \%$ \\
\hline Hint & & 4 & 3 & $16.7 \%$ & $16.7 \%$ \\
\hline
\end{tabular}

The quantitative data in Table 6 demonstrates that the use of direct strategies outweighed that of conventionally indirect strategies in terms of frequency, $57.1 \%$ and $47.6 \%$ respectively. This conflicts with the findings of Nguyen (2019) proposing that indirectness is the most popular request strategy among Vietnamese EFL students. One possible explanation for these controversial results may root from the differences in addressees of these two studies. In Nguyen (2019), the professors are all Vietnamese university teachers while in the present research, there is a diversity in the nationality of the professors. Moreover, all selected participants have at least one-semester study-aboard experience, which could affect their thinking pattern and writing styles. However, it should be noticed that the variation is insignificant.

There are no significant differences in the use of request strategies between two genders, although females tended to use conventionally indirect way while males preferred both imperative statements and indirect strategies. These findings, again, are in the same vein with other researchers for the fact that women often choose the indirect approach in verbal communication to mitigate the face-threatening acts (e.g. Holmes, 1995; Lakoff, 1975; Shams \& Afghari, 2011).

Moreover, the imperative statement is mostly identified with "please" and embedding syntactic modifiers used by both male and female as in the example in Appendix 3. However, female participants extensively employ "please" in all requests. Nevertheless, Vietnamese male students also take advantage of this lexical modifier in their writing in spite of low frequency in use, which is the same as Biesenbach-Lucas's (2007) report about NNS's habit of using "please". 
The use of "please" indicates some remarkable culture-specific features in communication in Vietnamese context. Culturally and linguistically, Vietnamese politeness heavily replies on lexical means, and honorific is one of the most indispensable politeness indexes which are directed to the hearer (Le, 2011). It is compulsory to add the honorific marker "a" at the end of sentences to show respect to addressees whose ranking and social status is higher. Furthermore, the marker "xin" (please) is believed to reduce the imperative act by downplaying the speaker (Do, 1994). Thus, by ingraining this notion of politeness in their brains, Vietnamese students overuse "please" as a replacement for "ạ" and "xin" when it comes to English language writing to express their respect to the addressees.

As for other lexical-syntactic modifiers, the researchers reported the result in Table 7. The tick (x) means the participants apply the modifier at least once in their email writing, and participant 1,2,10,11,12 are, as reported above, English-major students.

\section{Table 7. The use of syntactic and lexical modifier of each participant}

\begin{tabular}{|c|c|c|c|c|c|c|c|c|c|}
\hline \multirow[t]{2}{*}{ No } & \multicolumn{3}{|c|}{$\begin{array}{l}\text { Syntactic } \\
\text { modifiers }\end{array}$} & \multicolumn{6}{|c|}{ Lexical modifiers } \\
\hline & $\frac{\ddot{E}}{\tilde{E}}$ & 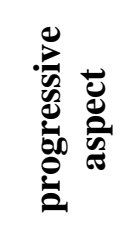 & 包 & please & downtoners & 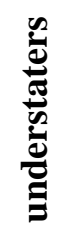 & 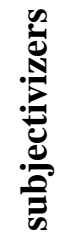 & & hedges \\
\hline 1 & $\mathrm{X}$ & $\mathrm{X}$ & $\mathrm{X}$ & $\mathrm{X}$ & $\mathrm{X}$ & & $\mathrm{X}$ & & $\mathrm{X}$ \\
\hline 2 & $\mathrm{X}$ & $\mathrm{X}$ & $\mathrm{X}$ & $\mathrm{X}$ & $\mathrm{X}$ & $\mathrm{X}$ & $\mathrm{x}$ & & $\mathrm{X}$ \\
\hline 3 & $\mathrm{X}$ & & $\mathrm{X}$ & $\mathrm{X}$ & & & & & $\mathrm{X}$ \\
\hline 4 & & & $\mathrm{x}$ & & & & & & $\mathrm{X}$ \\
\hline 5 & & & & $\mathrm{X}$ & & & & & $\mathrm{X}$ \\
\hline 6 & $\mathrm{X}$ & & $\mathrm{X}$ & $\mathrm{X}$ & & & & & $\mathrm{X}$ \\
\hline 7 & $\mathrm{X}$ & $\mathrm{X}$ & $\mathrm{X}$ & $\mathrm{X}$ & & & $\mathrm{x}$ & & $\mathrm{X}$ \\
\hline 8 & & & $\mathrm{X}$ & $\mathrm{X}$ & & & & & \\
\hline 9 & $\mathrm{X}$ & & $\mathrm{X}$ & $\mathrm{X}$ & & & $\mathrm{X}$ & & $\mathrm{X}$ \\
\hline 10 & $\mathrm{X}$ & & $\mathrm{x}$ & $\mathrm{x}$ & & & & & $\mathrm{X}$ \\
\hline 11 & $\mathrm{X}$ & $\mathrm{X}$ & $\mathrm{x}$ & $\mathrm{X}$ & & & $\mathrm{x}$ & & $\mathrm{x}$ \\
\hline 12 & $\mathrm{X}$ & $\mathrm{X}$ & $\mathrm{X}$ & & $\mathrm{X}$ & $\mathrm{X}$ & $\mathrm{x}$ & & $\mathrm{X}$ \\
\hline
\end{tabular}

Table 7 depicts a strong preference for embedding and hedges, followed by past tense modifiers. As explained earlier, embedding is associated with a direct request (i.e. imperative statements), and hedges including modal verbs (could, would, may, should) or hesitation words (seem, I think, as far as I know, I was wondering). The past tense emerged exclusively in fixed phrases such as "would you please", "could you please", "I was wondering" and "I was thinking".

Interestingly, there is a remarkable distinctiveness in modifier usage between Englishmajors and students pursuing other fields. Out of five English-majored students, four of them (participant $1,2,11,12$ ) flexibly employ diverse modifiers in their email writing comparing to their non-English-major peers. Among non-English-major learners, participant 7 who majored in Supply Chain Management also employs these linguistic devices tactfully and responsively in response to email writing contexts. In general, the comparison between students holding different undergrad majors demonstrates the role of linguistic knowledge and socio-pragmatics mentioned by Biesenbach-Lucas (2007) and Baugh (2011). The fact that English-major students do not stick to particular request patterns attributes to their higher English competence and more exposure to Western culture than students from other academic 
disciplines. At the same time, students from other majors favor some fixed phrases due to their limitation in language competence, especially linguistic knowledge.

\section{CONCLUSION}

The current study delves into the politeness pattern of Vietnamese EFL learners in academic writing emails regarding their gender and major. Different from Nguyen's (2019) limited email corpus only from English-major female students sending to two Vietnamese university lecturers, this study successfully overcomes these drawbacks by investigating emails from diverse majors and genders. Additionally, the recipients are indeed varied as regards to their cultural background, which allows researchers an opportunity to discuss more about L1-L2 pragmatic factors. More importantly, there are considerable implications drawn from the current research because of the different research approach. While Nguyen (2019) merely concentrates on email structure and quantified findings without much satisfying discussion, this study fully exploits and interprets the use of syntactic and lexical devices and the directness of the request act from both qualitative and quantitative approaches. Qualitative approach in the current study enables the researchers to generate further discussions with adequate explanation for English email patterns of Vietnamese EFL learners.

Overall, the selected participants exhibit a high level of imposition with formal terms of address, salutation and effective use of supporting sentences - explanation to establish contextualized and mutual understanding with professors. These findings are in line with Hamiloğlu and Emirmustafafaoğlu's (2017) research on Turkish EFL undergraduates. Regarding request acts, conflicting with Nguyen's (2019) statement, this study suggests that directness strategies (especially imperative statements) are more favored than conventionally indirectness strategies. The overuse of "please" and other hedges, is detected in both genders, which is the same as Biesenbach-Lucas's (2007) studies. All of these politeness strategies evidently root from Vietnamese notion of politeness which overpraises respectfulness and formality when corresponding with high-status addressees. This confirms the pragmatic and culture transferring phenomenon of EFL learners in English communication.

This study also discovers that there are no significant differences between genders, which confirms Mohammadi \& Tamimi's (2014) results. However, it should be noted that female participants somehow prefer conventional indirectness when making a request. Thus, they adopt more formal terms of address, thanking and closing remarks than males, entailing the purpose of mitigating face-threatening acts and concern for addressee's face (same as reported in Lakoff (1975); Shams \& Afghari (2011)). Furthermore, contradicted to the report of Nguyen (2019), surprisingly, males sometimes employ "promising a reward" and "giftgiving" strategies to impel the addressee to accept the request.

By analyzing the use of modifiers, there exists considerable distinctiveness between English-majored and non-English-majored students. English-major participants seem to be more confident and flexible when employing a variety of syntactic-lexical devices whereas participants in other academic fields confine with fixed phrases. This dissimilarity discloses the role of linguistic and socio-pragmatic competence in request email writing, upholding the theory of Baugh (2011) and Biesenbach-Lucas (2007).

One of the implications of this study is that it successfully sheds some light on the socio-pragmatic use of politeness strategies employed by Vietnamese EFL students. Although it is impossible to generalize, the present research concludes some far-reaching pedagogical implications in language teaching in Vietnam. In the era of e-communication, academic emails have become a prioritized choice for professor-student interaction owing to its convenience and cost-effectiveness. However, the aforementioned findings reveal some drawbacks in email English writing skill of Vietnamese learners, namely the overuse of "please", fixed phrases in every communication context and wrong use of honorific terms. Admittedly, it is difficult for students to neglect the influence of L1 pragmatic and notion of 


\section{Politeness of Vietnamese Students in Writing Request Email in English: a Course-based and Socio- \\ pragmatic Study}

politeness when it comes to English writing. Especially, as reported in Thi and Yeh (2020), English learning materials in Vietnam are remarkably deficient in social and situational appropriateness and authenticity. This may attribute to the unnatural and improper use of linguistic devices in real-life situations. Nevertheless, EFL learners need to be aware of the distinctiveness between their mother tongue, culture and addressee's language, culture to avoid communication failure. Socio-pragmatic knowledge should be equally important to linguistic knowledge to ensure the appropriate use of language. Thus, "language educators over the world have the responsibility to contribute towards inter-socio-cultural understanding and to help their students in the development of their pragmatic competences" (Nassar \& Al-Ghrafy, 2020, p.79).

There were shortcomings of this study that need to be addressed and further improved. Although the participants are purposely selected according to certain characteristics, heterogeneousness of the subjects was not satisfied. All of the participants are from Northern Vietnam, hence, they are not diverse in terms of geographical features. Besides, the corpus is still relatively small $(n=42)$, which may affect the generalizability of the results. For future studies, a substantial size of email corpus from randomized and culturally disparate participants should be conducted to fill in the gap in literature on Vietnamese and English email compositions in Vietnamese context.

\section{REFERENCES}

Baugh, J. (2011). What works in academic request email: a genre analysis with teacher and student perspectives (Doctoral dissertation). Colchester, UK: University of Essex.

Biesenbach-Lucas, S. (2007). Students writing emails to faculty: An examination of e-politeness among native and non-native speakers of English. Language Learning \& Technology, 11(2), 59-81.

Blum-Kulka, S. (1987). Indirectness and politeness in requests: Same or different. Journal of Pragmatics, 11, 131-146.

Blum-Kulka, S., \& Olshtain, E. (1984). Requests and apologies: A cross-cultural study of speech act realisation patterns (CCSARP). Applied Linguistics, 5, 196-213.

Blum-Kulka, S., House, J., \& Kasper, G. (1989). Investigating cross-cultural pragmatics: An introductory overview. In S. Blum-Kulka, J. House, \& G. Kasper (Eds.), Cross-cultural pragmatics: Requests and apologies (pp. 1-34). Norwood, NJ: Ablex Publishing.

Brown, P., \& Levinson, S. (1987). Politeness: Some Universals in Language Usage. Cambridge: Cambridge University Press.

Chen, C. E. (2001). Making e-mail requests to professors: Taiwanese vs American students. Paper presented at the Annual Meeting of the American Association for Applied Linguistics, St-Louis, MO.

Chew, C. L. G. (2011). Politeness in Vietnam. In Dániel Z. Kádár \& Sara Mills (eds.) Politeness in East Asia - Theory and Practice (pp. 208-225). Cambridge: Cambridge University Press.

Cutting, Joan (2002). Pragmatics and Discourse: A resource book for students. London: Routledge.

Do, Q. V. (1994). Tiếng Việt Tuyệt Vời. (Wonderful Vietnamese). Toronto. Canada: Làng Văn.

Elmianvari, A. \& Kheirabadi, R. (2013). The study of EFL students' requests based on politeness theory. Journal of Language Teaching and Research, 4(2), 375-385.

Fairclough, N. (1989). Language and power. London: Longman 
Félix-Bradefer, J. C. (2005). Indirectness and politeness in Mexican requests. In D. Eddingotn (ed.), Selected proceeding of the 7th Hispanic Linguistics Symposium (pp. 66-78). Sommervile, MA: Cascadilla Proceedings Project.

Hamiloğlu, K. \& Emirmustafafaoğlu, K. (2017). A sociolinguistic investigation on (im)polite email requests of Turkish EFL students. The Journal of International Lingual, Social and Educational Sciences, 3(2), 191-207.

Hieu, L. T. (2015). Confucian Influences on Vietnamese Culture. Vietnam Social Sciences, 5(169), 71-82.

Holmes, J. (1995). Women, Men and Politeness. New York: Longman.

Holtgraves, T., \& Yang, J. (1992). Interpersonal underpinnings of request strategies: General principles and differences due to culture and gender. Journal of Personality and Social Psychology, 62(2), 246-256.

International Office of Goethe University Frankfurt am Main (n.d.). How can I contact a lecturer. Retrieved November 8th, 2019 from https://www.goethe-universityfrankfurt.de/59008937/Lecturer_ENG.pdf.

Jansen, F., \& Janssen, D. (2010). Effects of positive politeness strategies in business letters. Journal of Pragmatics, 42(9), 2531-2548.

Kim, A. H. (2011). Politeness in Korea. In Kadar, D. \& Mills, S. (eds), Politeness in East Asia (pp. 176-207). Cambridge: Cambridge University Press.

Lakoff, R. (1975). Language and Woman's place. New York: Harper \& Row.

Le, P. T. (2011). Transnational variation in linguistic politeness in Vietnamese: Australia and Vietnam (Doctoral Dissertation). Victoria University, Australia. Retrieved October 29th, 2019 from http://vuir.vu.edu.au/17945/1/Phuc_Thien_Le.pdf

Lee, D. Y. W. (2008). Corpora and discourse analysis: new ways of doing old things. In Bhatia, V. K., Flowerdew, J. \& Jones, R. H. (eds), Advances in Discourse Studies (pp. 86-99). New York, NY: Routledge.

Leech, G. N. (1983). Principles of pragmatics. London. Longman.

Luong, H. V (1987). Plural markers and personal pronouns in Vietnamese person reference: An analysis of pragmatic ambiguity and native models. Anthropological Linguistics, 29(1), 49-70.

Miike, Y. (2006). Non-Western theory in Western research? An Asia-centric agenda for Asian communication studies. The Review of Communication, 6(1-2), 4-31.

Mohammadi, M. \& Tamimi, S. H. (2014). Native speakers' assessment of (im)politeness of nonnative speakers' requests. International Journal of Research Studies in Language Learning, 3(4), 23-40.

Nassar, H. M. A. \& Al-Ghrafy, A, M. Gh. (2020). The understandable English conversational implicatures by Ymenin EFL Unversity Learners. International Journal of Language and Literary Studies, 2(1), 65-80.

Nguyen, M. T. (2019). Exploring university students' politeness via Vietnamese students' emails of request. International Journal of Research in English Education, 4(3), 84-99.

Nguyen, T. D. P. (2011). Van hoa xung ho cua Nguoi Viet (Vietnamese rules of address). Ky yieu hoi theo Nghien cuu va giang day Vietnam hoc va tieng Viet. Retrieved October 29th

from http://www.vns.edu.vn/images/6_NGHIEN_CUU/LICH_SU_XA_HOI/NguyenThiDiem Phuong/1.Van-hoa-xung-ho-cua-nguoi-Viet.pdf 
Nguyen, T. T. M. \& Ho, G. A. L. (2013). Request and politeness in Vietnamese language. International Pragmatics Association, 23(4), 685-714.

Ogiermann, E. (2009). Politeness and indirectness across cultures: A comparison of English, German, Polish and Russian requests. Journal of Politeness Research, 5(2), 189-216.

Petty, R. E. \& Caccioppo, J. T. (1984). The effects of involvement on responses to argument quality and quantity. Journal of Personality and Social Psychology, 46(1), 69-81

Rahmani, E \& Rahmany, R. (2014). Politeness strategies and politeness markers in email request sent by Iranian EFL learners to professors. International Journal of Language Learning and Applied Linguistics World, 5(1), 183-197.

Rajagopalan, K. (2016). Request sequences: The intersection of grammar, interaction and social context. Word, 62(4), 281-283.

Searle, J. R. (1975). Indirect speech acts. In Cole, P. \& Morgan, J. L. (eds.), Syntax and semantics: Vol. 3. Speech Acts. (pp. 59-82). New York: Academic Press.

Shams, R. and Afghari, A. (2011). Effects of Culture and Gender in Comprehension of Speech Acts of Indirect Request. English Language Teaching, 4(4), 279-287.

Stubbs, M. (1996). Text and Corpus Analysis. Oxford: Blackwell.

Thi, T. T. M. \& Yeh, A. (2020). Keeping it real: Vietnamese-English pragmatic representations in EFL textbook. International Journal of Language and Literary Studies, 2(1), 1-20.

Tseng, C. H. (2016). E-politeness: An analysis of Taiwanese EFL learners' email discourse on request strategies. International Journal for 21th Century Education, 3 (Special Issue 'Language Learning and Teaching), 35-62.

Vu, T. T. H. (1997). Politeness in modern Vietnamese: A sociolinguistic study of Hanoi speech community (Unpublished Doctoral Thesis). Canada, Toronto: University of Toronto.

Watts, R. (2003). Politeness. Cambridge, UK: Cambridge University Press.

Yu, K-A. (2011). Culture-specific concepts of politeness: Indirectness and politeness in English, Hebrew and Korean requests. Intercultural Pragmatics, 8(3), 385-409.

\section{AUTHORS' BIOS:}

Thi Minh Trang Pham is an English teacher in the Faculty of Foreign Languages of Vietnam Maritime University, Vietnam and currently obtaining her Master of Art in English in Wenzao Ursuline University of Languages, Taiwan. Her research concerns English as a Foreign Language (EFL) learning and teaching, Sociocultural Teaching Approach and Applied Linguistics.

Dr. Aiden Yeh is an Asst. Professor and Director of Academic Cooperation \& Exchange Section at Wenzao Ursuline University of Languages, Taiwan, where she also serves as Academic Adviser for Southeast Asian Studies Program. She has a PhD in Applied Linguistics (Birmingham University, UK) and MSc in ELT Management (Surrey University). 


\section{APPENDIX 1}

\section{Example of High/ Low Level of Imposition Email}

High level of imposition email:

Dear Professor [last name], (getting attention-formal address)

I was asking you about possible Linguistics topics for my MA thesis. (Small talk) I have already got a list of topics from my supervisor, which, however, are mostly related to Second Language Acquisition. (Supporting sentence - Explanation) (Only) if it is convenient, could you also point me towards some possible Linguistics topics that I can do my MA thesis in? (Request) That would be very much appreciated. (Supporting sentence - promise a reward)

Also, as of the solution to one of the exercises, why is "wordstock" (sic) purism? (I was thinking it is compounding. (Supporting sentence - Explanation) Please correct me (Request)).

Thank you so much for your time and also for the lessons, which have been super eyeopening. (Thanking/ Supporting sentence - Gift giving)

Sincerely, (Closing conversation)

[student's full name] (Salutation)

Moderate or low level of imposition email:

Hi Ms. [first name] (Getting attention - Informal address)

I am [student's full name] from [student's class].

The following attachment is my answer to the student questionnaire. (Supporting sentence - Explanation)

Please checked and assess it! (Request)

Thank you! (Thanking)

Your (sic) sincerely, (Closing conversation)

[Student's name] (Salutation)

Email 1

\section{APPENDIX 2}

\section{Participant 5's Emails}

Dear professor, (Getting attention-formal address)

Firstly, I apologize for absent (sic) last morning because I went to the cultural experience program for exchange students. (Supporting sentence - Apologize) Besides, this is my practice paragraphs. Can you please mark it? (Request) I checked very carefully for the spelling mistakes.

I am looking forward to hearing from you. (Closing signal)

Yours faithfully, (Closing remark)

[Student's full name]

Email 2

Dear teacher [first name], (Getting attention - formal address)

I am going to a cultural experience program for exchange students hosted by the International Office tomorrow. (Supporting sentence - Explanation) I hope that it is still not too late to inform you. (Request)

Yours faithfully, (Closing remark)

[Student's full name]

Email 3

Dear professor [last name], (Getting attention - formal address) 
I am studying IELTS and I have a topic that I really can not (sic) write anything about it. (Supporting sentence - Explanation) Can you please give me some hints about the supporting ideas? (Request) Here is the topic:

"Because they receive not enough financial support, but also because of health problems (psychological and physiological), some old people can not (sic) take care of themselves. Do you think that young people should have the legal responsibility for supporting them?" (Supporting sentence - Explanation)

I look forward to hearing from you! (Closing signal)

Your (sic) faithfully, (Closing remark)

[Student's full name]

APPENDIX 3

Example of the Usage Of "Please"

- If there is anything else I need to do, please let me know, too. (Participant 1)

- If you need any further information or any discussions in person, please let me know. (Participant 2)

- Please inform me if any errors occur when you move my home directory. (Participant 3)

- Please, kindly find the attach (sic) file (Participant 4)

- If any further inquire, please let me know, I can come to discuss with you more. (Participant 6)

- Please confirm this appointment so that we could meet on next Friday (12/10) (Participant 11)

The habit of using "please" also appeared in most of conventionally indirect requests.

- Would you please check and mark it? (Participant 2)

- $\quad$ There is just a tiny error with my first name in the list. That is [name] (not [name]). Could you please correct it? (Participant 2)

- Can you please give me some hints about the supporting ideas? (Participant 5)

- Could you please check whether this email was sent to a wrong address email? (Participant 7)

- Could you suggest which one is more suitable for discussion, please? (Participant 10)

- On Tuesday next week, can we please have the test a little later, i.e. not at exactly 6:00 PM, but for example, at 6:15 PM? (Participant 12) 